\title{
"A character does not make a genus, but the genus makes the character": three-taxon statement analysis and intuitive taxonomy
}

\author{
Evgeny V. MAVRODIEV ${ }^{1, *} \&$ Olga V. YURTSEVA ${ }^{2}$ \\ ${ }^{1}$ University of Florida, Florida Museum of Natural History, Museum Road and Newell Drive, \\ Dickinson Hall, 301, Gainesville, FL, 32611, USA \\ ${ }^{2}$ M.V. Lomonosov Moscow State University, Department of Higher Plants, 1-12, Leninskie Gory, \\ 119234, Moscow,Russia \\ ${ }^{*}$ Corresponding author: evgeny@ufl.edu \\ 2Email: olgayurtseva@yandex.ru \\ ${ }^{1}$ urn:1sid:zoobank.org:author:EA16F665-354D-4D52-845B-341DEB506D1A \\ ${ }^{2}$ urn:lsid:zoobank.org:author:B532893B-945A-4342-AB52-1A2DA307EFCD
}

\begin{abstract}
Three-taxon statement analysis (3TA) is a method that may help to formalize the taxonomical intuition of the synapomorphy of the clade as a combination of its diagnostic traits, even if each trait, if taken separately, may be found in one or many other taxa of the same relationship. Using example based on the real morphological data, we are showing that 3TA can recognize clade in case of the complete lack of it synapomorphies, as optimized under the criterion of standard parsimony.
\end{abstract}

Keywords. Three-taxon statement analysis, intuitive taxonomy, synapomorphy, diagnostic traits.

Mavrodiev E.V. \& Yurtseva O.V. 2017. "A character does not make a genus, but the genus makes the character": three-taxon statement analysis and intuitive taxonomy. European Journal of Taxonomy 377: 1-7. https://doi.org/10.5852/ejt.2017.377

This should be particularly clear to taxonomists. For anyone who has dealt with large and peculiarly diverse varieties of living forms, it is impossible to disregard that each group of organisms is characterized with its own distinct image. This image is not subject to verbal description. The only method of objective characterization of the group lies in the listing of its diagnostic features, i.e. those features that directly distinguish this group from others. However, such features are scarce... This "general image" is none but the type of group.

B.S. Kuzin (1992). The decadence of Systematics, I. (The first author has translated the passage; bold and italic formatting added).

As summarized in Williams \& Ebach (2016), when commenting on Scotland \& Steel (2015), character compatibility analysis in systematics captures the "intuitive taxonomic practice of recognizing taxa based on conserved non-homoplastic characters" (Scotland \& Steel 2015: 493). According to Williams \& 
Ebach (2016), who presented evidence of compatibility analysis within many different contexts (e.g., Williams \& Ebach 2008, 2016), the definition of Scotland \& Steel (2015) is not relevant to actual intuitive taxonomic practice. As stated in Williams \& Ebach (2016), the taxonomic practice is based on the different procedure - on the finding of the taxa using the combinations of the characters, which are not necessarily compatible or unique.

In support of this view, Williams \& Ebach (2016) citing Nelson (1996, 2004: 137), who in turn was summarizing Antoine Laurent de Jussieu (1748-1836), who clearly stated that the combination of the characters actually "constitutes the essential and invariable character [=synapomorphy]" (italics is ours), even if "each character, taken separately", may be found in one or many other taxa of the same relationship.

As a recent relevant example of this, we note similar passages in Mavrodiev et al. (2014), Crespo et al. (2015) and Yurtseva et al. (2016), who all found or summarized that unique combinations of partially overlapping morphological characters can successfully be used as a diagnostic for the taxonomic recognition of the intuitively clear genera of the Iridaceae (previously circumscribed with the "broadly" defined Iris (incl. Belamcanda), Aloe (Aloeaceae), Asparagaceae subfam. Scilloideae tribe Ornithogaleae (= Hyacinthaceae subfam. Ornithogaloideae), Atraphaxis (Polygonaceae), Centaurium (Gentianaceae), Chenopodium (Amaranthaceae), Coreopsis (Asteraceae), Nothofagus (Nothofagaceae), Typha (Typhaceae), among others.

However, is there an exact method that may help researchers to invoke taxonomic intuition of "actual synapomorphy" as a combination of traits? As mentioned by Williams \& Ebach (2016), three-taxon statement analysis (3TA), one of the two approaches to Hennigian cladistics (e.g., Williams \& Siebert 2000), originally proposed by Nelson \& Platnick (1991), is just such a method.

As was stressed by Williams \& Ebach (2008: 210), the 3TA “... sees systematic data as reducible to the simplest relational form, the three-taxa statement or minimal relations: hence, the statement $\mathrm{A}(\mathrm{BC})$, where B and C share a relationship to the exclusion of A...". Therefore, 3TA based on the original way dealing with information: on the representation and analysis of the relationships directly (Williams \& Ebach 2008).

3TA can recognize clades, for which the standard (conventional) Maximum Parsimony (MP) analysis provides no unequivocal synapomorphies, as was clearly demonstrated by Nelson (1996) (see also Williams \& Ebach 2005, 2008, 2016), using the hypothetical matrices of the binary characters, or even no synapomorphies, as optimized under the criterion of conventional parsimony (e.g., Nelson \& Platnick 1991, see also Mavrodiev 2016).

To illustrate this analytical power of the 3TA, we would like to provide an example not from hypothetical data, but from an actual comprehensive taxonomic study based on recent treatment of the genus Atraphaxis L. (Polygonaceae) and the related taxonomical entities (Yurtseva et al. 2016). A few words are still necessary to describe the proper context.

Recent molecular phylogenetic analyses of Tavakkoli et al. (2015) and Yurtseva et al. (2016) discovered the sister position of Polygonum subsect. Spinescentia Boiss. (included by Tavakkoli et al. (2015) in Atraphaxis as Atraphaxis sect. Polygonoides S. Tavakkoli, Kaz. Osaloo \& Mozaff.) to Atraphaxis L. s. str., as well as the sisterhood of the clade (Polygonum subsect. Spinescentia plus Atraphaxis) and genus Bactria Yurtseva \& Mavrodiev (A. ovczinnikovii (Czukav.) Yurtseva). However, due to the vague and extremely complicated morphology, the morphological cladistic treatment of Atraphaxis and its closely related taxonomic entities has never been performed until the recent past (Yurtseva \& Mavrodiev 2017; Yurtseva et al. 2017). 
Recently, Polygonum subsect. Spinescentia has been accepted at the generic rank as Persepolium O.V. Yurtseva \& E.V. Mavrodiev (Yurtseva \& Mavrodiev 2017; Yurtseva et al. 2017). This genus comprises several narrow endemics of West and South Iran (reviewed in Tavakkoli et al. 2015 and Yurtseva et al. 2016, 2017). By applying standard MP analysis and 3TA to the comprehensive 27 characters' morphological dataset (Table S1 (available as an electronic Supplement and taken from Yurtseva et al. 2017: 194-194, see their Appendices 2 and 3)) of the widely distributed genus Atraphaxis (incl. A. section Ovczinnikovia), we have confirmed that the monophyletic Persepolium is sister to the narrowly defined Atraphaxis and the position of this taxon is strongly supported (Fig. 1).

Observing Table S1, it is easy to see that the characters 1, 2, 4, 8, 12, 16, 18, 19 and 26 provide evidence for the clade (Persepolium) and/or are optimized as synapomorphies of this clade under the standard MP criterion (Yurtseva et al. 2017: 179-181).

But can we recognize the clade (Persepolium), if all the supported conventional characters 1, 2, 4, 8, 12 , $16,18,19$ and 26 (Table S1) are excluded from future analyses? In such cases the only intuitively clear, but verbally inexpressible "general image" (eidos) of Persepolium, as well as the set of the combinations of non-unique diagnostic features, nested "around" this "image", may be considered by somebody as a source of taxonomic evidence for this section.

The conventional MP analysis (as well as a Maximum likelihood and Bayesian methods) is unable to recognize the clade (Persepolium) if standard characters 1, 2, 4, 8, 12, 16, 18, 19 and 26 (Table S1) were excluded from the analysis (Fig. 1C). Due to the lack of the conventional synapomorphic characters none of the six trees based on the reduced matrix contains the clade (Persepolium). However under the same conditions, 3TA still found the clade (Persepolium) with 100\% confidence (Fig. 1D).

We would like to stress that neither of the three-taxon statements that support the clade (Persepolium) are derived from the "evident" conventional characters (one, two, four, eight, 12, 16, 18, 19, and 26 in the Table S1), because all these were excluded from the matrix before the three-taxon permutation had been performed. Therefore, within the framework of the 3TA, neither of the "unique" characters is actually necessary for the recognition of the clade (Persepolium). This clade exists, but no conventional characters (Table S1) need define it.

Contrary to Richter (2016) and others (summarized in Richter 2016), this result is clearly arguing in favor of Nelson's concepts of either taxon or homology as a relationship (summarized in Williams \& Ebach 2008 and Nelson 2011): "If synapomorphies are understood as relationships rather than homologues, then homologies, synapomorphies, taxa, and relationships become equivalent invisibilities" (Nelson 2011: 139).

But what do "invisibilities" mean in this context? Why not the impossibility of formalizing the vision verbally? The impossibility to "translate" the clear intuition of the general image of the plant into a list of standard characters?

If the last interpretation of Nelson's view is correct, then the pure aesthetic as well as Husserlian contexts (Husserl 1913; Seamon 1998; see also Schuetz 1959 and Uehlein 1992 among others) of 3TA are possible. Numerous philosophical contexts, however, are still relevant to discuss the 3TA (e.g., Mavrodiev 2016).

In this manner, the characters do not actually make the genus, but rather the genus gives the characters, which follow the distinct image (eidos) of the genus, not subject to verbal description (Kuzin 1992). 
A. Standard MP: complete matrix

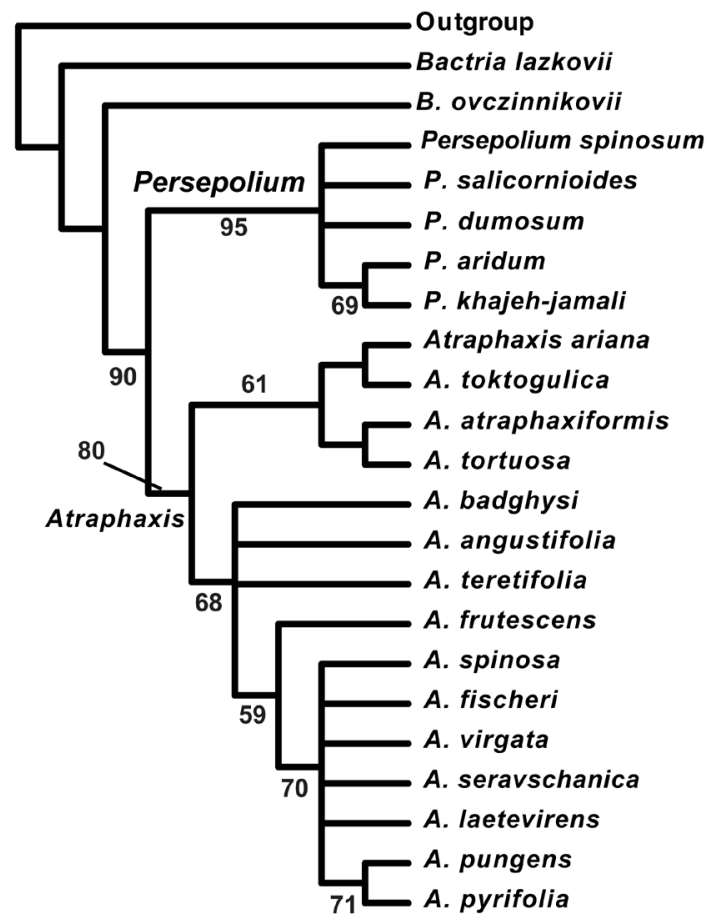

C. Standard MP: reduced matrix

(contains no synapomorphies for Persepolium)

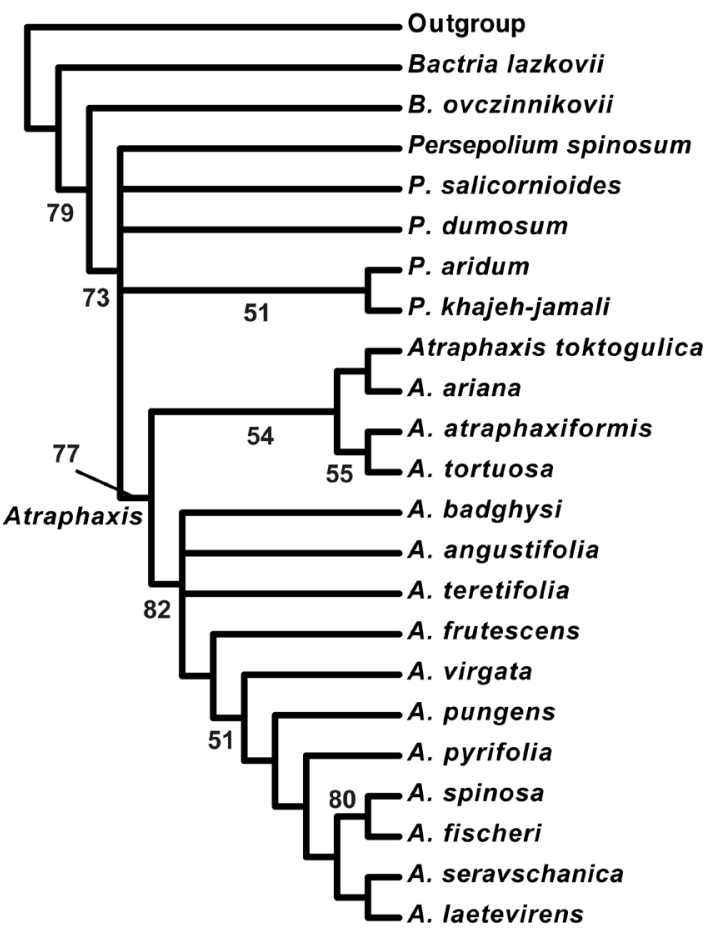

B. 3TA: complete matrix

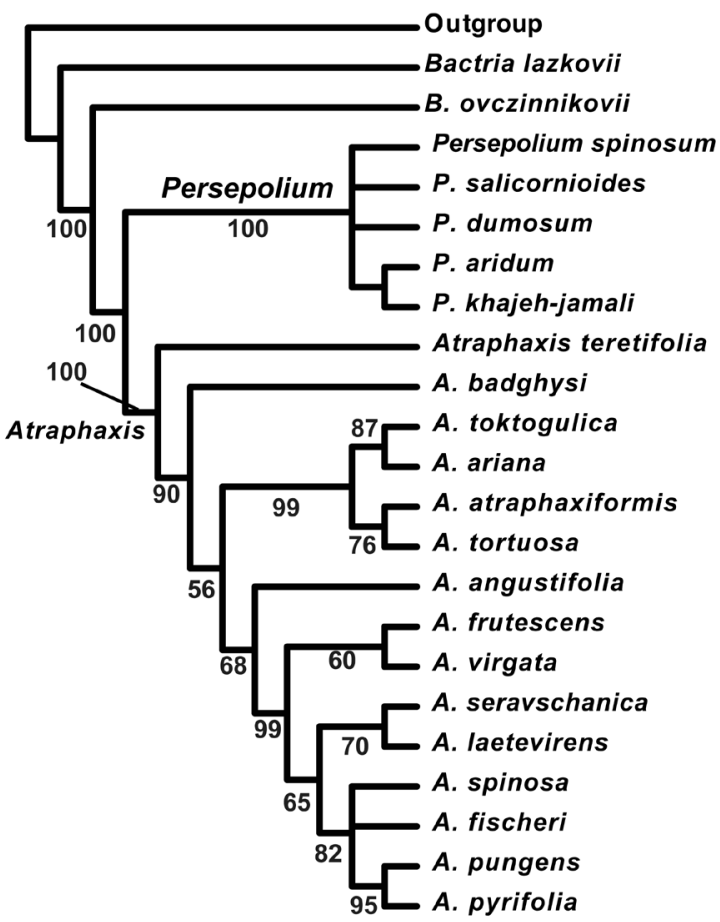

D. 3TA: reduced matrix (all standard synapomorphies of Persepolium have been removed before 3TS permutations (C.))

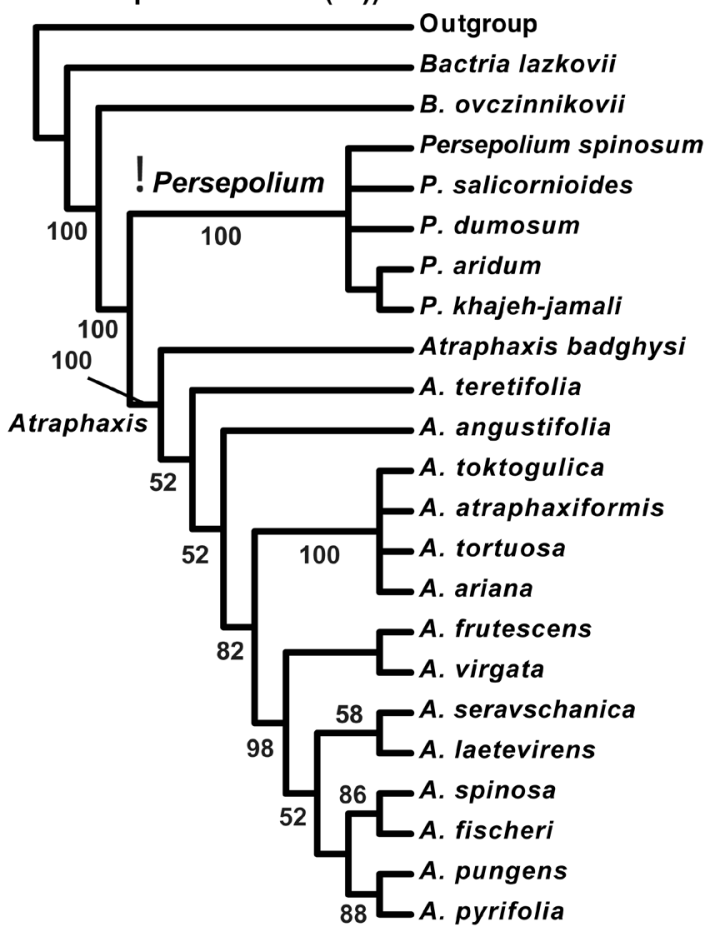


MARODIEV E.V. \& YURTSEVA O.V., Three-taxon statement analysis and intuitive taxonomy

\section{Acknowledgments}

Dr. David M. Williams (the Natural History Museum, London, UK) and Prof. Malte C. Ebach (University of New South Wales \& the Sydney's Australian Museum, AU) are greatly acknowledged for their helpful comments and related discussion. The morphological study (OVY) was carried out in accordance to Government order for the Lomonosov Moscow State University (project No. AAAA-A16-116021660045-2).

\section{References}

Crespo M.B., Martinez-Azorin M. \& Mavrodiev E.V. 2015. Can a rainbow consist of a single colour? A new comprehensive generic arrangement of the 'Iris sensu latissimo' clade (Iridaceae), congruent with morphology and molecular data. Phytotaxa 232: 1-78. https://doi.org/10.11646/phytotaxa.232.1.1

Husserl E. 1913. Ideas Pertaining to a Pure Phenomenology and to a Phenomenological PhilosophyFirst Book: General Introduction to a Pure Phenomenology. Martinus Nijhoff Publishers, Boston. [Reprinted in 1982.]

Kuzin B.S. 1992. The decadence of Systematics, I. Nature (Priroda- published by Russian Academy of Science): 80-88. [In Russian; Publication was prepared by Dr. I. Ya. Pavlinov (Zoological Museum of M. V. Lomonosov Moscow State University)]

Maddison W.P. \& Maddison D.R. 2011. Mesquite: a modular system for evolutionary analysis. Version 3.31 .

Fig. 1. A. Strict consensus of 61 most parsimonious phylogenetic trees; tree length $=90$ steps; $C I=0.6000$; $\mathrm{RI}=0.8302$, recovered from a standard cladistic analysis (MP) (Fitch Parsimony) of the complete conventional morphological matrix of Atraphaxis s. 1.(TableS1).All27 unordered(non-additive) characters are parsimony informative. B. Strict consensus of two nested most parsimonious hierarchies of patterns; length $=8328$ steps $\mathrm{CI}=0.8521 ; \mathrm{RI}=0.8264$ ), recovered from a MP analysis of the three-taxon statement representation of the complete conventional 27 characters' morphological matrix of Atraphaxis s. 1. (Table S1). The number of 3TSs (characters) is equal to 7096, all are parsimony-informative. C. Strict consensus of six most parsimonious phylogenetic trees; tree length $=56$ steps; $\mathrm{CI}=0.6071 ; \mathrm{RI}=0.8370$, recovered from a MP analysis of the reduced conventional 18 characters' morphological matrix of Atraphaxis s. 1. (Table S1) with the characters one, two, four, eight, 12, 16, 18, 19, and 26 excluded. D. Strict consensus of two nested, most parsimonious hierarchies of patterns; length $=5844$ steps; $\mathrm{CI}=0.8665 ; \mathrm{RI}=0.8460$ ), recovered from a MP analysis of the three-taxon statement representation of the reduced conventional 18 characters' morphological matrix of Atraphaxis s. 1. (Table S1) with characters 1, 2, 4, 8, 12, 16, 18, 19 and 26 excluded. The number of 3TSs (characters) is equal to 5064, all are parsimony-informative. All MP analyses as in PAUP* 4.0a150 (Swofford 2002) were conducted using either conventional matrices or TAXODIUM's output 3TS NEXUS files with a heuristic search of 1000 random addition replicates (saving no more than 100 trees per replicate), and the TBR branch swapping/MulTrees option into effect. Branches with a minimum length of zero were collapsed. The three-taxon statement analysis (3TA) of the unordered morphological matrix was established after it three-taxon (3TS) Williams-Siebert (WS) representation (Williams \& Siebert 2000) using TAXODIUM v. 1.2 (Mavrodiev \& Madorsky 2012). The 3TS permutations were performed with the following command: taxodium input_file_name. csv -ium -ob-og -nex The value of the operational outgroup was fixed as a value of Bactria lazkovii. All 3TSs were weighted uniformly and treated as "ordered" (Wagner Parsimony). The bootstrap resampling of both conventional and 3TS matrices have been performed as described in Mavrodiev \& Madorsky (2012). The diagnostic traits are optimized using Mesquite (Maddison \& Maddison 2011). 
Mavrodiev E.V. 2016. Dealing with propositions, not with the characters: the ability of three-taxon statement analysis to recognise groups based solely on 'reversals', under the maximum-likelihood criteria. Australian Systematic Botany 29: 119-125. https://doi.org/10.1071/SB16006

Mavrodiev E.V. \& Madorsky A. 2012. TAXODIUM Version 1.0: a simple way to generate uniform and fractionally weighted three-item matrices from various kinds of biological data. PLoS One 7 (11): e48813. https://doi.org/10.1371/journal.pone.0048813

Mavrodiev E.V., Martinez-Azorin M., Dranishnikov P. \& Crespo M.B. 2014. At least 23 genera instead of one: the case of Iris L. s.l. (Iridaceae). PLoS One 9 (8): e106459. https://doi.org/10.1371/journal.pone.0106459

Nelson G. 1996. “Nullius in verba”. Self-published, New York.

Nelson G. 2004. Cladistics: its arrested development. In: Williams D.M. \& Forey P.L. (eds) Milestones in Systematics: 127-148. CRC Press, Boca Raton, London, New York and Washington, DC

Nelson G. 2011. Resemblance as evidence of ancestry. Zootaxa 2946: 147-141.

Nelson G. \& Platnick N.I. 1991. Three-taxon statements - a more precise use of parsimony? Cladistics 7: 351-366. https://doi.org/10.1111/j.1096-0031.1991.tb00044.x

Richter S. 2016. Homology and synapomorphy-symplesiomorphy-neither synonymous nor equivalent but different perspectives on the same phenomenon. Cladistics 7: 1-5. https://doi.org/10.1111/cla.12180

Schuetz A. 1959. Type and eidos in Husserl's late philosophy. Philosophy and Phenomenological Research 20: 147-165. https://doi.org/10.2307/2104353

Scotland R.W \& Steel M. 2015. Circumstances in which parsimony but not compatibility will be provably misleading. Systematic Biology 64: 492-504. https://doi.org/10.1093/sysbio/syv008

Seamon D. 1998. Goethe, nature, and phenomenology: an introduction. In: Seamon D. \& Zajonc A. (eds) Goethe's Way of Science - A Phenomenology of Nature: 1-15. State University of New York Press, New York.

Swofford D. L. 2002. PAUP*. Phylogenetic Analysis Using Parsimony (*and other methods), v. 4. Sinauer Associates, Sunderland, Massachusetts.

Tavakkoli S., Osaloo S.K., Mozaffarian V. \& Maassoumi A.A. 2015. Molecular phylogeny of Atraphaxis and the woody Polygonum species (Polygonaceae): taxonomic implications based on molecular and morphological evidence. Plant Systematics and Evolution 301: 1157-1170. https://doi.org/10.1007/s00606-014-1140-7

Uehlein F.A. 1992. Eidos and eidetic variation in Husserl's Phenomenology. In: Spitzer M. et al. (eds) Phenomenology, Language \& Schizophrenia: 88-102. Springer, New York. https://doi.org/10.1007/978-1-4613-9329-0_6

Williams D.M. \& Ebach MC. 2005. Drowning by numbers: rereading Nelson's "Nullius in Verba". Botanical Review 71: 415-447. https://doi.org/10.1663/0006-8101(2005)071[0415:DBNRNN]2.0.CO;2

Williams D.M. \& Ebach M.C. 2008. Foundations of systematics and biogeography. Springer, New York. https://doi.org/10.1111/j.1096-0031.2010.00335.x

Williams D.M. \& Ebach M.C. 2016. What is intuitive taxonomic practise? Systematic Biology syw094. https://doi.org/10.1093/sysbio/syw094

Williams D.M. \& Siebert D. J. 2000. Characters, homology and three-item analysis. In: Scotland R.W. \& Pennington R.T. (eds) Homology and Systematics: Coding Characters for Phylogenetic Analysis: 183208. Chapman \& Hall, London, New York. 
Yurtseva O.V. \& Mavrodiev E.V. 2017. Genus Persepolium nom. provis. (Polygonaceae, Polygoneae): evidence from the results of the standard maximum parsimony analysis and the three-taxon statement analysis of the comprehensive morphological dataset. In: Sokoloff D. et al. (eds) Conference on Taxonomy and Evolutionary Plant Morphology Dedicated to the 85 th Anniversary of V.N.Tikhomirov, January 31-February 3, 2017. M.V. Lomonossov Moscow State University, Moscow, Russia.

Yurtseva O.V., Kuznetsova O.I., Mavrodieva M.E. \& Mavrodiev E.V. 2016. What is Atraphaxis L. (Polygonaceae, Polygoneae): cryptic taxa and resolved taxonomic complexity instead of the formal lumping and the lack of morphological synapomorphies. PeerJ 4. e1977 https://doi.org/10.7717/peerj.1977

Yurtseva O.V., Severova E.E. \& Mavrodiev E.V. 2017. Persepolium (Polygoneae): A new genus in Polygonaceae based on conventional Maximum Parsimony and Three-Taxon Statement analyses of a comprehensive morphological dataset. Phytotaxa 314 (2): 151-194. https://doi.org/10.11646/phytotaxa.314.2.1

Manuscript received: 24 February 2017

Manuscript accepted: 16 May 2017

Published on: 11 December 2017

Topic editor: Koen Martens

Desk editor: Jeroen Venderickx

Printed versions of all papers are also deposited in the libraries of the institutes that are members of the EJT consortium: Muséum national d'Histoire naturelle, Paris, France; Botanic Garden Meise, Belgium; Royal Museum for Central Africa, Tervuren, Belgium; Natural History Museum, London, United Kingdom; Royal Belgian Institute of Natural Sciences, Brussels, Belgium; Natural History Museum of Denmark, Copenhagen, Denmark; Naturalis Biodiversity Center, Leiden, the Netherlands; Museo Nacional de Ciencias Naturales-CSIC, Madrid, Spain; Real Jardín Botánico de Madrid CSIC, Spain. 